\title{
Constraints in Poultry Production faced by Poultry Owners in Bhandara District, India
}

\author{
A. P. Chawke*, P. A. Kahate, D. M. Sul, R. R. Shelke and S. P. Nage \\ Department of Animal Husbandry and Dairy Science, \\ Dr. Panjabrao Deshmukh Krishi Vidyapeeth, Akola (MS), India \\ *Corresponding author
}

The present investigation entitled "Growth Performance and Production Cost of Poultry Farm Maintained at Bhandara District" under Bhandara

Keywords

Constraints, Poultry, Owner, Production, Risk

Article Info

Accepted:

12 December 2020

Available Online:

10 January 2021 district adopted three village clusters viz Bhandara district having seven talukas was undertaken for the present study namely Tumsar, Mohadi Bhandara, Sakoli, Lakhani, Pauni and Lakhandur. Three villages selected randomly for the present investigation. High chick cost problem 100\%, $75 \%$ and $00 \%$ faced by small, medium and large poultry owners, respectively. $75 \%$ of small, $50 \%$ of medium and $40 \%$ of large poultry owners was faced the problem of Integration. $100 \%$ of small, $75 \%$ of medium and $20 \%$ of large poultry owners was faced the problem of entry of middleman. While, studying marketing it was necessary to make a glance on problem faced by owners during marketing of poultry. In respect of marketing major problem reported was the price fluctuation by $100 \%$ poultry owners.

\section{Introduction}

Poultry farming is the processes of rising domesticate birds such as chickens ducks, turkeys and geese for the purpose of forming meat or eggs for food. Poultry - mostly chickens are farmed in great numbers. Farmers raise more than 50 billion chickens annually as a source of food, both for their meat and for the eggs. Chickens raised for eggs are usually called layers while chickens raised for meat are often called broilers. Poultry is one of the fastest growing segments of the agricultural sector in India currently. As per industry sources, the domestic poultry market in India is valued at between USD 6-7 Billion of which chicken (meat and eggs) account for 90 per cent of the market. Poultry farming is seen as one of the most significant activities for the rural people. According to 
National Sample Survey (NSS) report (GOI, 2006) on livestock ownership, landless marginal and small farmer accounted for about $90 \%$ of the population having $85 \%$ of the total poultry stock. India has 1.23 billion people and the number is growing every year. The focus is on "Development" meaning Good Food, Better Health \& Living conditions to everyone. People spend more money on food when they earn more. Healthy food at attractive price will be the issue in focus. Eggs and chicken are accepted by all communities and are available at the most reasonable prices. Within a span of 25 years, the egg production has gone up to 70 billion from few millions and the broiler production has gone to 3.8 million tons from nowhere. Customers have over the years developed a perception that fresh poultry meat purchased as live bird and slaughtered on site in their presence is better in quality.

Additionally, poor transport, infrastructure and lack of cold chain facilities currently limit the feasibility of handling significant volumes of chilled or frozen products. As poultry is sensitive to both income and price, the recent trends towards faster growth in per capita incomes; as well as declining real prices of poultry are likely to contribute to more rapid growth in poultry consumers.

\section{Materials and Methods}

The data for the present investigation entitled "Growth Performance and Production Costs of Poultry Farm maintained At Bhandara District" was undertaken during 2019-20 collected the data from the difference poultry owners in Bhandara district of seven talukas. The data regarding the location, various management practices and constraints encountered while the poultry owners we are collected by personnel interview with poultry owners.
Good and well maintained of 21 poultry units of different capacities were selected purposively for multipurpose, which have maintained clean, good records and therefore serve the purpose of obtaining requisite information for economic analysis and cover the objectives of present study. Selected units then categorized into small, medium and large units according to poultry unit size.

\section{Results and Discussion}

\section{Constraints faced by poultry owners}

\section{Constraints faced by poultry owners during rearing}

One of the objectives of the study was identify the problems faced by the poultry owners during rearing of poultry are presented in table 2 and graphically represented in Fig. 1.

From Table 2,high chick cost problem 100\%, $75 \%$ and $00 \%$ faced by small, medium and large poultry owners, respectively. Also, the high feed cost problems among 75\%, 75\% and $20 \%$ faced by small medium and large poultry owners, respectively. In the low quality chick there are no problems to any of the poultry owners during study. The low quality feed for small, medium and large poultry owners faced the problem was $75 \%$, $75 \%$, and $20 \%$, respectively. In disease infection, the small, medium and large owner was faced $75 \%, 37.5 \%$ and $40 \%$ problems, respectively. In case of labour shortage, the small, medium and large owners faced $25 \%$, $37.5 \%, 100 \%$ problems, respectively. The small, medium and large poultry owners faced heat problem in summer was62.5\%, 75\%, and $40 \%$, respectively. In care of chick, the small, medium and large owners faced $12.5 \%$, $37.5 \%$ and $00 \%$ problems, respectively. In case of electricity, only small owners were faced $37.5 \%$, of problem. In loan facility, 
small and medium owners were faced $87.5 \%$, and $25 \%$ of problem. In case of government subsidy, the small owner was faced $12.5 \%$ of problem also medium owner was faced $62.5 \%$ of problems and the large owners was faced $100 \%$ of problems. In lack of insurance protection only small and medium owners was faced $100 \%$ and $25 \%$ of problems. It was observed that in rearing, problems was faced $55.20 \%, 43.75 \%$ and $64 \%$ faced by small medium and large owners, respectively.

The results of present investigation are observed similar by the results reported by previous research workers like Islam et al., $(2012)^{[4]}$, Anang et al., (2013) $)^{[2]}$, Ali et al.,
$(2015)^{[7]}$ and Maoba $(2016)^{[3]}$ about the constraints faced by poultry owners in poultry production and marketing.

\section{Constraints faced by poultry owners during marketing}

The problems faced by poultry owners during marketing of poultry are presented in table 3 and graphically represented in fig. 2 .

It is observed from table 3 that, the problems faced by the selected farmers during marketing $100 \%$ of small, medium and large owners was faced the problem of price fluctuation.

Table.1 Distribution of sample according to Poultry unit size

\begin{tabular}{|c|c|c|}
\hline Sr.No. & Unit Size & Criteria \\
\hline $\mathbf{1}$ & Small unit & $1-2000$ birds \\
\hline $\mathbf{2}$ & Medium unit & $2001-4000$ birds \\
\hline $\mathbf{3}$ & Large unit & 4000 birds and above \\
\hline
\end{tabular}

Table. 2 Problems faced by the poultry owners during rearing of poultry

\begin{tabular}{|c|l|c|c|c|}
\hline $\begin{array}{c}\text { Sr. } \\
\text { No. }\end{array}$ & $\begin{array}{c}\text { Problem faced by farmers } \\
\text { during rearing }\end{array}$ & $\begin{array}{c}\text { Small owners } \\
\mathbf{( N = 8 )}\end{array}$ & $\begin{array}{c}\text { Medium owners } \\
(\mathbf{N}=8)\end{array}$ & $\begin{array}{c}\text { Large owners } \\
(\mathbf{N}=5)\end{array}$ \\
\hline $\mathbf{1}$ & High chick cost & $8(100 \%)$ & $6(75 \%)$ & $0(00 \%)$ \\
\hline $\mathbf{2}$ & High feed cost & $6(75 \%)$ & $6(75 \%)$ & $1(20 \%)$ \\
\hline $\mathbf{3}$ & Low quality chick & $0(00 \%)$ & $0(00 \%)$ & $0(00 \%)$ \\
\hline $\mathbf{4}$ & Low quality feed & $4(75 \%)$ & $4(75 \%)$ & $1(20 \%)$ \\
\hline $\mathbf{5}$ & Disease infection & $6(75 \%)$ & $3(37.5 \%)$ & $2(40 \%)$ \\
\hline $\mathbf{6}$ & Labour shortage & $2(25 \%)$ & $3(37.5 \%)$ & $5(100 \%)$ \\
\hline $\mathbf{7}$ & Heat in summer & $5(62.5 \%)$ & $4(75 \%)$ & $2(40 \%)$ \\
\hline $\mathbf{8}$ & Care of chick & $1(12.5 \%)$ & $3(37.5 \%)$ & $0(00 \%)$ \\
\hline $\mathbf{9}$ & Electricity & $3(37.5 \%)$ & $0(00 \%)$ & $0(00 \%)$ \\
\hline $\mathbf{1 0}$ & Loan facility & $7(87.5 \%)$ & $2(25 \%)$ & $0(00 \%)$ \\
\hline $\mathbf{1 1}$ & Government subsidy & $1(12.5 \%)$ & $5(62.5 \%)$ & $5(100 \%)$ \\
\hline $\mathbf{1 2}$ & Lack of Insurance protection & $8(100 \%)$ & $4(25 \%)$ & $0(00 \%)$ \\
\hline & Total & $\mathbf{5 5 . 2 0 \%}$ & $\mathbf{4 3 . 7 5 \%}$ & $\mathbf{6 4 \%}$ \\
\hline
\end{tabular}

(Figures in parentheses are percentage to total) 
Table.3 Problems faced by the poultry owners during marketing of poultry

\begin{tabular}{|c|l|c|c|c|}
\hline $\begin{array}{c}\text { Sr. } \\
\text { No. }\end{array}$ & $\begin{array}{l}\text { Problem faced by owners } \\
\text { during marketing }\end{array}$ & $\begin{array}{c}\text { Small owners } \\
(\mathbf{N = 8})\end{array}$ & $\begin{array}{c}\text { Medium owners } \\
(\mathbf{N = 8})\end{array}$ & $\begin{array}{c}\text { Large Owners } \\
(\mathbf{N = 5})\end{array}$ \\
\hline $\mathbf{1}$ & Price fluctuation & $\begin{array}{c}8 \\
(100 \%)\end{array}$ & $\begin{array}{c}8 \\
(100 \%)\end{array}$ & $\begin{array}{c}5 \\
(100 \%)\end{array}$ \\
\hline $\mathbf{2}$ & Lack of storage facility & 4 & 2 & 0 \\
$(50 \%)$ & $(25 \%)$ & 1 \\
\hline $\mathbf{3}$ & Lack of processing & $(100 \%)$ & 5 & $(20 \%)$ \\
\hline $\mathbf{4}$ & Integration & 6 & $(62.5 \%)$ & 2 \\
& & $(75 \%)$ & 4 & $(40 \%)$ \\
\hline $\mathbf{5}$ & Entry of middleman & 8 & $(50 \%)$ & $(20 \%)$ \\
\hline $\mathbf{6}$ & Lack of co-operative & $(100 \%)$ & $(75 \%)$ & 2 \\
& marketing facility & 3 & 4 & $(40 \%)$ \\
\hline & Average & $(37.5 \%)$ & $(50 \%)$ & $(\mathbf{3 6 . 6 6 \% )}$ \\
\hline
\end{tabular}

(Figures in parentheses are percentage to total)

Fig.1 The problems faced by poultry owners during rearing of poultry

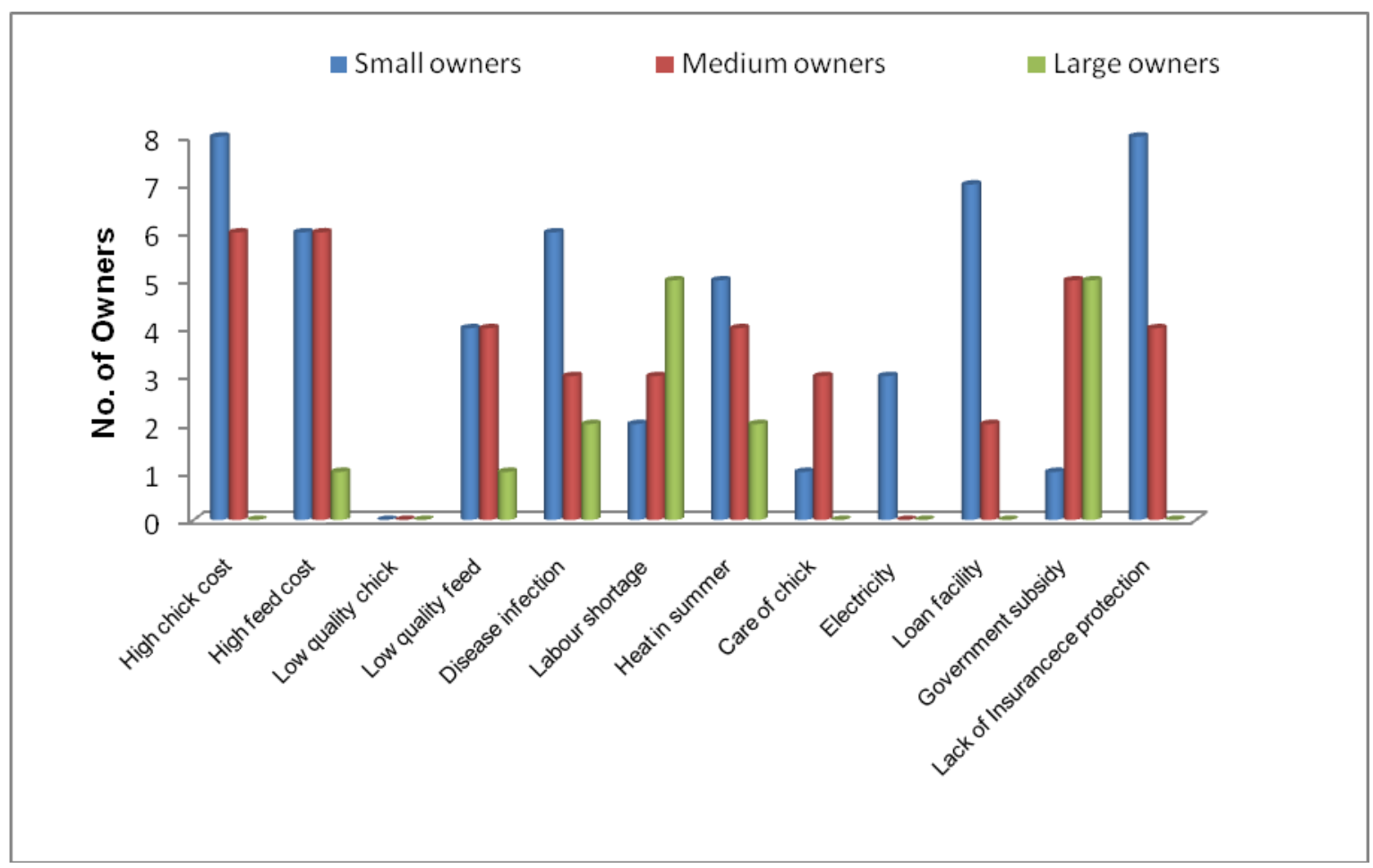


Fig.2

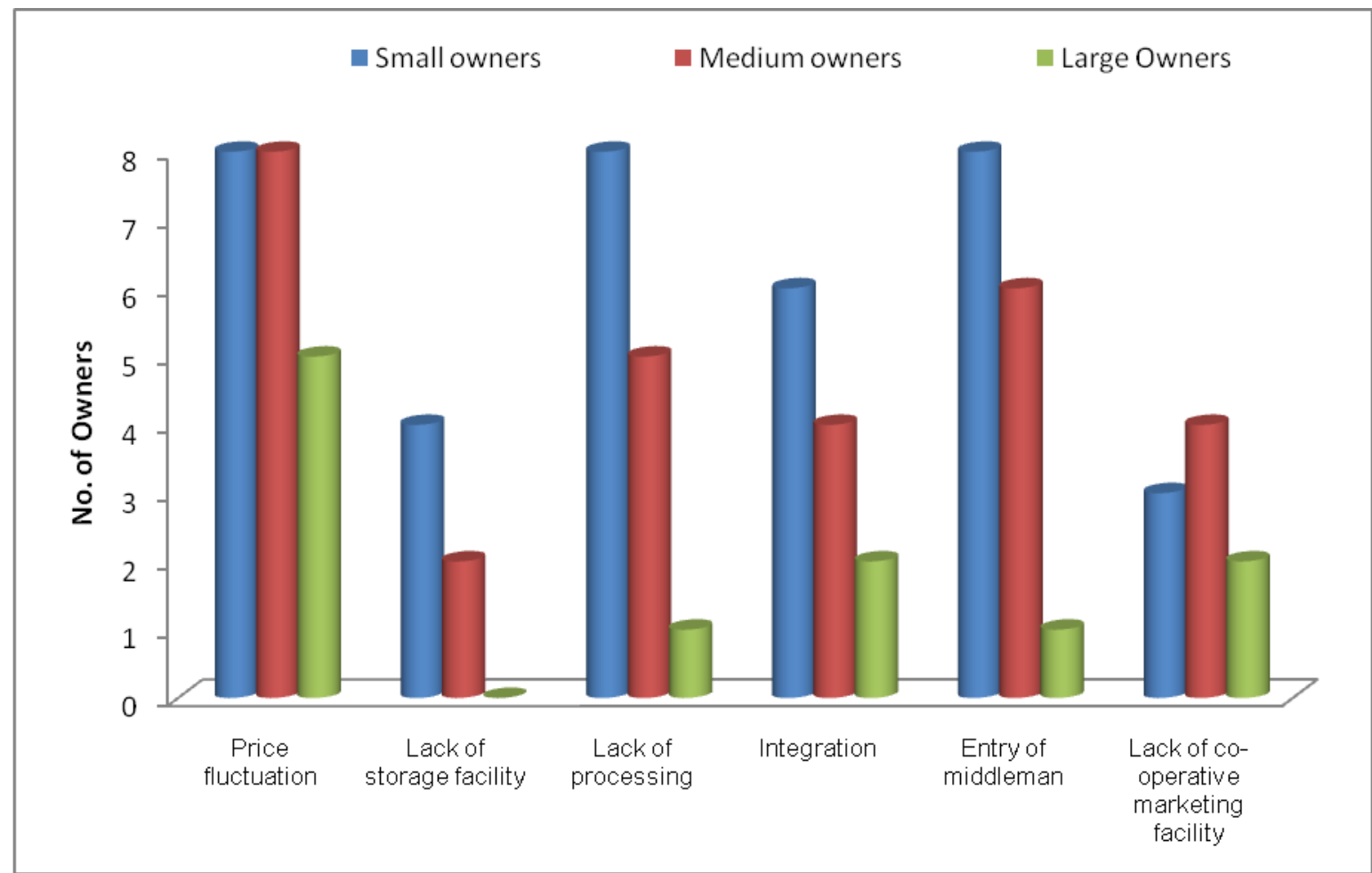

Only $50 \%$ of small and $25 \%$ of medium owners was faced the problem of lack of storage facility. $100 \%$ of small, $62.5 \%$ of medium and $20 \%$ of large poultry owners was faced the problem about lack of processing. $75 \%$ of, $50 \%$ and $40 \%$ of small, medium and large poultry owners was faced the problem of Integration, respectively. $100 \%$ of small, $75 \%$ of medium and $20 \%$ of large poultry owners was faced the problem about entry of middleman. As well as $37.5 \%$ of small, $50 \%$ of medium and $40 \%$ of large owners was faced the problem of lack of co-operative marketing facility during poultry production. While, studying marketing it was necessary to make a glance on problem faced by owners during marketing of poultry.

In respect of marketing major problem of price fluctuation was the by $100 \%$ poultry owners. There is maximum problem faced by small and medium farmers than large poultry owners.
Taru et al., (2010) ${ }^{[6]}$ examined the economics of broiler production in Meme Division of Cameroon. Major problems facing broiler producers were low market prices, high cost of feed, veterinary services, transportation, lack of access to credit and extension services.

The results reported by previous research workers like Anang et al., (2013) [2], Malarvizhi and Geetha (2015) ${ }^{[5]}$, Ali et al., $(2015)^{[7]}$ and Maoba (2016) ${ }^{[3]}$ reported the similar results about the constraints faced by poultry owners in poultry production and marketing.

On the basis of findings of the present study it can be concluded that the poultry owners had faced the constraints during rearing are high chick cost, high feed cost, low quality chick, low quality feed, disease infection, labour shortage, heat in summer, care of chick, electricity, loan facility, government subsidy 
and lack of insurance protection. Also, constraints faced by poultry owners during marketing are price fluctuation, lack of storage facility, lack of processing, integration, entry of middleman and lack of co-operative marketing facility during poultry production in Bhandara district.

\section{References}

Ali, Y., S. Jahan, A. Islam, M. A. Islam (2015), Impact of socio-economic factors on production performance of small and medium size broiler farming in Bangladesh. Journal of New Sciences, Vol. 15(1), 479-487.

Anonymous, National Sample Survey Organization (NSSO) (2006), National Sample Survey 2005-2006 (62nd round) - Schedule 2.2 - Unorganized Manufacturing Sector in India.

Benjamin Tetteh Anang, Cosmos Yeboah and Anthony Amison Agbolosu (2013), Profitability of broiler and layer production in the Brong Ahafo region of Ghana, ARPN Journal of Agricultural and Biological Science, vol. 8(5) 423-430.

Malarvizhi, V and Geetha, K.T. (2015), Economic cost and profit assessment of poultry farming in Namakkal district. Journal of Management and Science, Vol. 5 (2), 42-55.

Maoba S. (2016), Production performance and profitability analysis of small scale layers project supported through casp in Germiston region, Gauteng Province, S. Afr. J. Agric. Ext., Vol. 44, (1) 2016: 42-49.

Saiful Islam, M., Md. AshrafulKabir and Ripon Kumar Dutta (2012), Productivity, cost benefit analysis, market prices and constraints to poultry farming in the northern districts of Bangladesh, J. Life Earth Sci., Vol. 7, 21-27.

Taru, G.E.Nkwi, A.I.Medugu and Reuben 2010. -Economics of Broiler Production in Meme Division of Cameroon\|, Journal of Agriculture Science, Vol.1 (2), 83-87.

\section{How to cite this article:}

Chawke, A. P., P. A. Kahate, D. M. Sul, R. R. Shelke and Nage, S. P. 2021. Constraints in Poultry Production faced by Poultry Owners in Bhandara District, India. Int.J.Curr.Microbiol.App.Sci. 10(01): 1390-1395. doi: https://doi.org/10.20546/ijcmas.2021.1001.165 